\title{
Performance estimation of a shallow foundation on an unsaturated expansive soil slope subjected to rainfall infiltration
}

\author{
Mengxi $\operatorname{Tan}^{1}$, and Sai K. Vanapalli ${ }^{1}$ \\ ${ }^{1}$ Department of Civil Engineering, University of Ottawa, Ottawa, Ontario, Canada
}

\begin{abstract}
In the last two decades, there has been a significant increase in infrastructure development on slopes of hilly regions of the world, due to population growth. There are many infrastructures on unsaturated expansive slopes, especially in semi-arid and arid regions. Rainfall infiltration is one of the major factors that contributes to the slope and infrastructure foundations failures on hilly slopes with unsaturated expansive soils. In the current study, a rational approach is proposed considering the combined influence of the foundation-slope behavior based on the principles of unsaturated soil mechanics. This is achieved by a novel numerical modelling approach using the commercial software Geo-studio to investigate the performance of strip foundation located on the top of the unsaturated expansive soil slope subjected to various rainfall infiltration conditions. Hydro-mechanical coupling analysis is conducted to evaluate the rainfall water infiltration influence combined with slope stability analysis using limit equilibrium method. Comparisons are made between both the foundation bearing capacity, slope stability before and after rainfall water infiltration. Different failure mechanisms of the foundation and slope system are presented with and without foundation loading for various rainfall scenarios. Results summarized in this paper are helpful for the geotechnical engineers for understanding the performance of shallow foundations on unsaturated expansive soil slopes considering the influence of rainfall infiltration conditions.
\end{abstract}

\section{Introduction}

The growth of population in various regions of world during the last five decades has promoted significant increases in human settlements on hilly regions. Due to this reason, especially during the last two decades, various infrastructures such as the residential structures, highways, pipelines and transmission towers with shallow foundations are constructed on hilly regions as service facilities. The design of the geotechnical infrastructure on the hilly regions are based on conventional soil mechanics principles assuming the soil is in a state of saturated condition. However, close to $40 \%$ of the Earth's land surface constitutes of unsaturated soils (Khalili et al. [1]). Traditional design methods may not provide reliable estimates of the performance of infrastructure on hilly regions that are typically in a state of unsaturated condition. Water infiltration associated rainfall is a major factor that triggers the unsaturated soil slope failures due to a decrease in the soil shear strength associated with a loss of matric suction. This problem can be more pronounced in unsaturated expansive soils since they are sensitive to the moisture content variations (Qi \& Vanapalli [2]). Therefore, special attention is required for foundation-expansive slope system taking account influence of rainfall conditions.

Foundations on slopes are designed either as conventional foundations or are considered as surcharge in a conventional slope stability problem (Pantelidis and Griffith [3] Baah-Frempong and Shukla [4]). Failure of foundation-slope system likely contribute to human casualties and significant economic losses. For example, the Po Shan landslides in 1972 has killed 138 people and lead to the damage of the several civil infrastructures on the slope (Choi et al. [5]). There are several studies undertaken during the last 50 years to understand the behavior of foundations-slope systems (Meyerhof [6], Shields et al. [7], Raj et al. [8], Dey et al. [9], Li et al.[10]). These studies provide valuable information for understanding the foundation-slope behavior taking account influence of various parameters such as the slope geometry and foundation positions. However, these studies focussed only on the behavior of saturated soils.

There are no studies reported in the literature to the best of the knowledge of the authors that consider combined influence of the foundation-slope behavior extending the principles of unsaturated soil mechanics. The foundation and slope under unsaturated condition are conventionally investigated, independently. Several investigators have contributed to the development of rational procedures for the design of shallow foundations in unsaturated soils during the last fifteen years (Vanapalli

\footnotetext{
* Corresponding author: Sai.Vanapalli@,uottawa.ca
} 
and Mohamed [11], Oh and Vanapalli [12], Le et al. [13], Kim et al. [14], Tang et al. [15], Mahmoudabadi and Ravichandran [16]). These studies are valuable in understanding the influence of matric suction on the bearing capacity and settlement behavior of soils. However, focus of these studies were directed to understand the behavior of foundations on level ground. More focused research is required for better understanding the performance of foundations on the unsaturated slope ground, especially in expansive soils considering the influence of hydro-mechanical behavior under different rainfall scenarios.

The slope stability of unsaturated soils have been widely investigated considering the influence of rainfall conditions (Qi \& Vanapalli [2], Ng et al. [17], Khan et al. [18]). These studies highlight how matric suction decreases in unsaturated soils due to rainfall infiltration which in turn contributes to a reduction of soil shear strength and slope factor of safety (FS). In addition, some of these studies provide rational interpretation of the slope stability by taking account of the hydro-mechanical behavior of expansive soils (Qi \& Vanapalli [2]). The results of these studies suggest that shallow surface failure is a common failure mechanism and may be associated to the cracks and fissures that form due to the evaporation in drying period and the water infiltration in rainy seasons (Qi \& Vanapalli [2], Khan et al.[18]). However, in the foundation-slope system, the possible failure mechanisms may not be limited to surface failure of the slope, but may also be accompanied with foundation bearing capacity failure. In other words, combined failure of slopefoundation system is possible due to the influence of rainfall. Such coupled influence of failures has not been comprehensively investigated in the literature extending the state-of-the-art understanding of the mechanics of unsaturated soils.

Therefore, in the current study, foundation and slope are combined analyzed as a system taking account the influence of rainfall infiltration with the aid of commercial software Geo-studio (Geo-Slope Int. Ltd [19]). The hydro-mechanical coupling analysis were performed for assessing the performance of a strip foundation located on expansive soil slope considering the influence of rainfall infiltration, which involved four different steps. As a first step, the in-situ analysis is undertaken to determine the initial stress and pore water pressure distribution. Then, the pore water pressure variations were estimated using SIGMA/W directly (Coupled stress/PWP analysis) for various rainfall conditions at four locations; namely: (1) at the slope top ground, (2) below the foundation, (3) at the middle of the slope, and (4) the slope toe. Such an approach can be considered to be a fully coupled analysis compared to that using SEEP/W followed by SIGMA/W analysis. In the third step, the load deformation analysis was investigated for the foundation followed using SLOPE/W to evaluate the slope FS. In the final step, different scenarios of slope stability failure were determined for three different conditions: (i) slope without foundation loading, (ii) slope with foundation subjected to ultimate bearing capacity loading (iii) slope with foundation subjected to allowable bearing capacity loading.
For rigorous analyses, the bimodal soil water characteristic curve (SWCC) which takes account of the influence of cracks has been included, in the numerical model. The relationships between the soil properties; namely, the variation of shear strength and modulus of elasticity with respect to the matric suction have also been considered in the model.

\section{Numerical study}

\subsection{Model set up and soil properties}

A typical shallow strip foundation with a width $B$ equal to $1 \mathrm{~m}$ located on a Regina clay slope with $10 \mathrm{~m}$ height and slope angle of $30 \mathrm{~m}$ is investigated in this paper (see Figure 1). The distance from the foundation edge to the slope crest is set as equal to the foundation width for a preliminary investigation. Yoshida et al. [20] investigations suggest that the active zone in Regina clay extends to a depth of $2.8 \mathrm{~m}$. Based on these results, the slope surface active zone is assumed to be $3 \mathrm{~m}$. Quadrilateral mesh has been used in the numerical modelling with mesh refinement in the active zone which is equal to $3 \mathrm{~m}$.

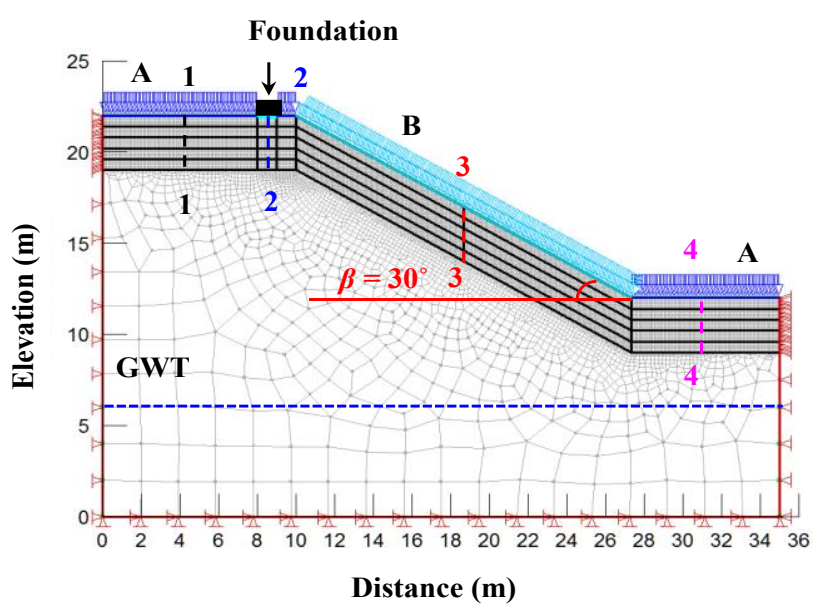

Fig. 1 Numerical model details

The soil water characteristic curves (SWCC) of both surface soil and sub-soil are shown in Figure 2a. Soil in the surface active zone is simulated as cracked soil. The cracks in expansive soil contribute to a dual porosity structure and likely exhibits a bimodal SWCC. The bimodal SWCC data in Figure 2a was derived from experimental investigations performed by Azam and Ito [21] on Regina expansive soil and was fitted by the spline function built in the Geo-studio software. The first and second air entry values are $10 \mathrm{kPa}$ and $300 \mathrm{kPa}$, respectively. The sub-soil, below the active zone depth is assumed as an intact soil. The sub-soil SWCC was obtained based on the bimodal SWCC that was obtained by superposition technique proposed by Li et al. [22]. The air entry value is $300 \mathrm{kPa}$ for the intact sub-soil.

Figure $2 \mathrm{~b}$ shows the soil hydraulic conductivity function used in the modelling. The coefficient of permeability data are obtained from the data provided by Shuai [23]. The spline function method that was used for 
SWCC fitting is also extended for this function. The surface soil hydraulic conductivity is assumed two orders larger than the sub-soil based on the study conducted by Qi and Vanapalli [2]. The saturated hydraulic conductivity of the surface layer is $5.66 \times 10^{-3} \mathrm{~m} /$ day.

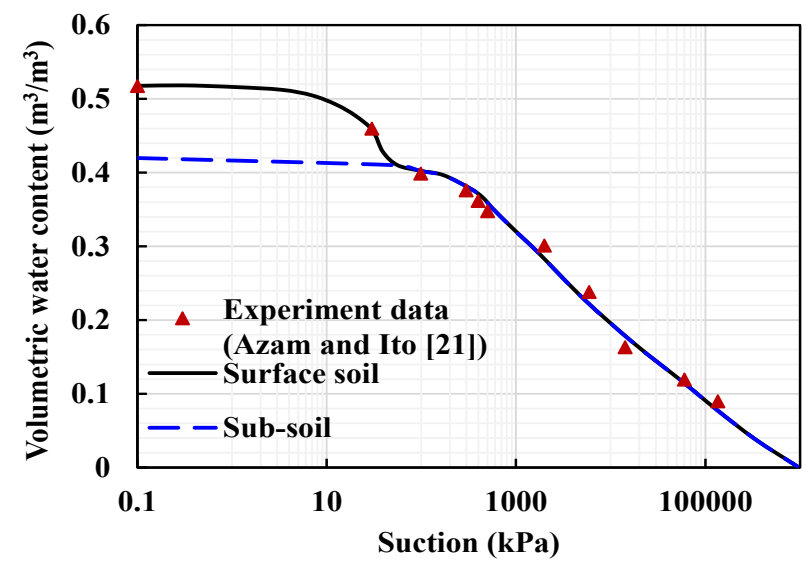

Fig. 2a SWCC of Regina clay

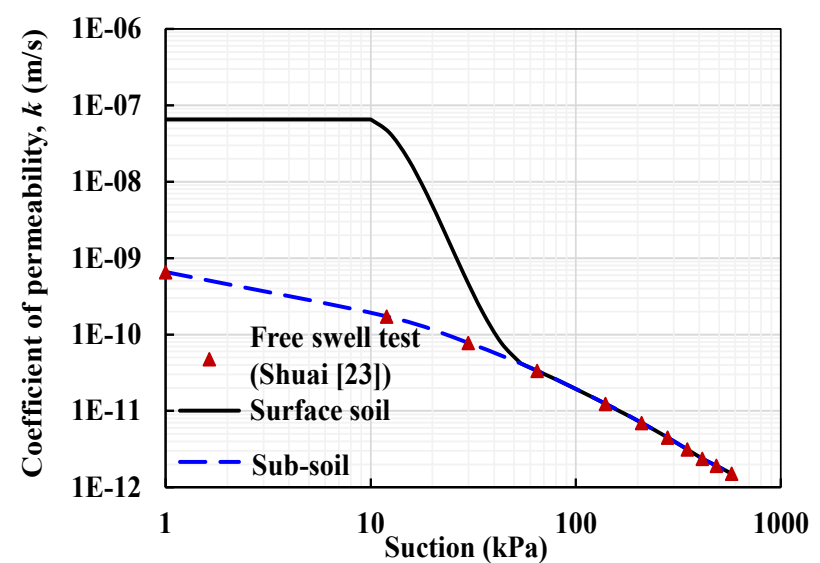

Fig. 2b Hydraulic conductivity of Regina clay

Fig. 2 The relationship between the SWCC and the hydraulic conductivity of the Regina clay.

The variation of unsaturated soil shear strength and elastic modulus with respect to soil suction are key information required for assessing the foundation behavior and slope stability. The shear strength, $\tau$, model proposed by Vanapalli et al. [24] shown in Eq. 1 is used in the present study.

$$
\tau=c^{\prime}+\left(\sigma_{\mathrm{n}}-u_{\mathrm{a}}\right) \tan \phi^{\prime}+\left(u_{\mathrm{a}}-u_{\mathrm{w}}\right)\left(\frac{\theta-\theta_{\mathrm{r}}}{\theta_{\mathrm{s}}-\theta_{\mathrm{r}}}\right) \tan \phi^{\prime}
$$

where $c^{\prime}, \phi^{\prime}$ are the shear strength parameters: saturated effective cohesion and effective internal friction angle, $\left(\sigma_{\mathrm{n}}\right.$ - $\left.u_{\mathrm{a}}\right)$ and $\left(u_{\mathrm{a}}-u_{\mathrm{w}}\right)$ are the net normal stress and suction, $\theta$ is the volumetric water content, $\theta_{\mathrm{s}}$ and $\theta_{\mathrm{r}}$ are respectively, the saturated and residual volumetric water contents. The elastic, perfectly-plastic model has been used for the surface soil. The Mohr-Coulomb yield criterion is the yield function for this elastic, perfectly-plastic model. Linear elastic model has been used for the sub-soil.

The elastic modulus of the unsaturated soil is estimated using the equation (Eq. 2) proposed by Oh et al. [25].

$$
E_{\text {unsat }}=E_{\text {sat }}\left[1+\alpha \frac{\left(u_{\mathrm{a}}-u_{\mathrm{w}}\right)}{\left(P_{a} / 101.3\right)}\left(S^{\beta}\right)\right]
$$

where $E_{\text {unsat }}$ and $E_{\text {sat }}$ are respectively the elastic modulus of unsaturated soil and saturated soil. $\alpha$ and $\beta$ are fitting parameters, values of $\alpha=0.1, \beta=2$ used in this study based on results from Adem and Vanapalli [26]. $P_{a}$ is the atmosphere pressure. The software used in this study does not facilitate in generating the relationship between the elastic modulus and the matric suction. For this reason, an approximation technique (Qi and Vanapalli [2]) is adopted in the numerical model combined with Eq. 2 for estimating the elastic modulus under rainfall. The active zone of the slope surface is divided into several layers. The average elastic modulus of each layer is calculated and updated based on the average matric suction of each layer obtained from the previous time interval. The other soil properties used in the numerical model are from Qi and Vanapalli [2], which are summarized in Table 1.

\begin{tabular}{|c|c|c|}
\hline Soil Properties & Surface soil & Sub-soil \\
\hline Effective cohesion, & 5 & 10 in \\
\hline$c^{\prime}(\mathrm{kPa})$ & & SLOPE/W \\
\hline $\begin{array}{l}\text { Effective internal friction } \\
\text { angle, } \phi^{\prime}\left(^{\circ}\right)\end{array}$ & 17.5 & $\begin{array}{l}17.5 \text { in } \\
\text { SLOPE/W }\end{array}$ \\
\hline Elastic modulus, $E(\mathrm{kPa})$ & Eq. 2 & 4000 \\
\hline Unit weight, $\gamma\left(\mathrm{kN} / \mathrm{m}^{3}\right)$ & 18.04 & 18.04 \\
\hline Poisson's ratio, $\mu$ & 0.4 & 0.4 \\
\hline
\end{tabular}

Table 1 Regina clay properties used in the model

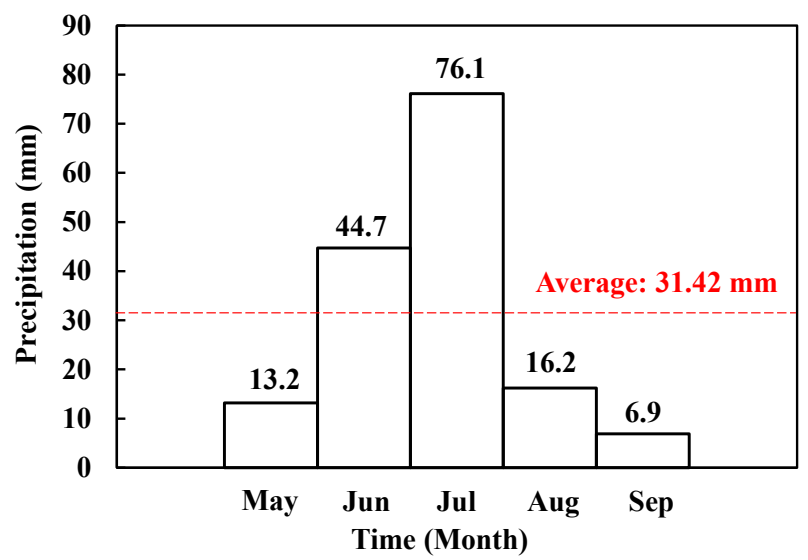

Fig. 3 Precipitation during the rainy season from May to September 21, 2020 in Regina, Canada

\subsection{Boundary conditions}

The initial ground water table (GWT) is assumed at a depth of $16 \mathrm{~m}$ from the top ground of the slope shown in Figure 1. The pore water pressure below the GWT at right and left lateral boundaries are under hydrostatic conditions. The initial rainfall boundaries are set along the surface of the slope with boundary A in Figure 1 on the top and toe of the slope and boundary B along the sloping ground. Boundary A is determined based on the average monthly precipitation recorded in Regina, Canada during the rainy season from May to September 21, 2020 shown in Figure 3. Therefore, a daily average rainfall influx boundary value, $I_{\mathrm{A}}$ equal $1.05 \times 10^{-3} \mathrm{~m}$ was applied as boundary A, along the top and toe ground of the slope for rainfall duration of 150 days ( 5 months). This influx value is slightly lower than the surface soil saturated hydraulic 
conductivity. The daily flux for boundary B which is normal to the sloping ground is calculated as $I_{\mathrm{A}} \cos \beta$ with a daily influx value of $9.09 \times 10^{-4} \mathrm{~m}$. 'No flow' boundary has been set on the slope ground beneath the foundation.

The mechanical boundaries are also applied in the coupling analysis. The horizontal displacement is fixed along the left and right vertical boundaries and both the vertical and horizontal displacement are fixed at the bottom boundary. Displacement control with a rate of $0.1 \mathrm{~m} /$ day has been applied beneath the foundation on the sloping ground while performing the foundation load deformation analysis.

\section{Results and discussion}

\subsection{Effect of rainfall on the pore water pressure}

Figure 4 summarizes the pore water pressure variations under the rainfall condition at four different locations. These locations are at the slope top, beneath the foundation, mid slope and slope toe shown in Figure 1 as section 1-1, 2-2, 3-3 and 4-4 respectively. Prior to the rainfall, the initial pore water pressure is under hydrostatic conditions with different magnitude at the four sections. The top ground of the slope (Sections 1-1, 2-2) has a large distance from the GWT and therefore the matric suction is higher (i.e. lower pore water pressure) than that at the toe of the slope. A sharp decrease has been found in the matric suction (i.e. increase in negative pore water pressure) from the surface of the slope in both section 11, 3-3 and 4-4 after 30 days of rainfall. At the same time, the no flow boundary below the foundation contributes to small changes in the pore water pressures at the surface layer of section 2-2, the lower layer in the active zone remains the same as the initial condition. Moreover, the pore water pressure profile of section 2-2 along the depth is slightly different from that of section $1-1,3-3$ and 4-4 until 120 days of rainfall. After120 days of rainfall, the pore water pressure remains almost the same at the surface of the soil in section 2-2. The wetting front, which is defined as the separation between the wetting zone and the initial condition in section 1-1, 3-3, 4-4, advances faster and deeper compared to that in section 2-2.

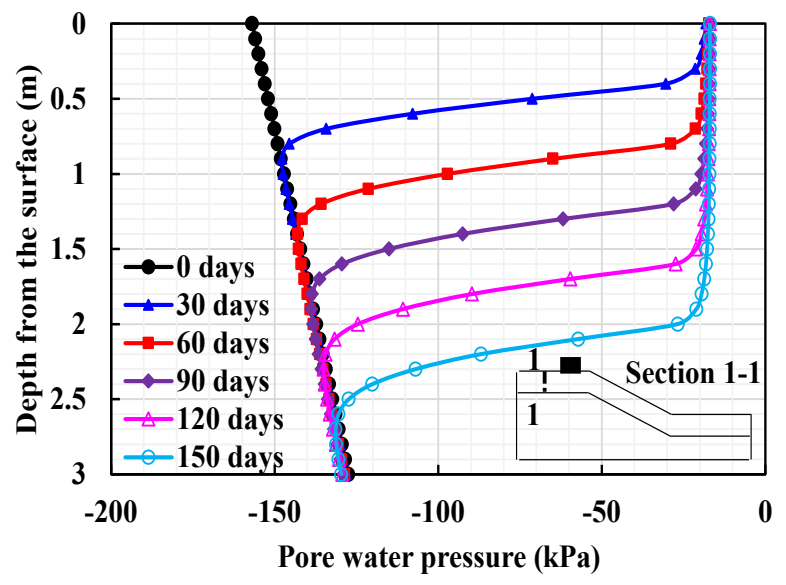

Fig. 4a Section 1-1

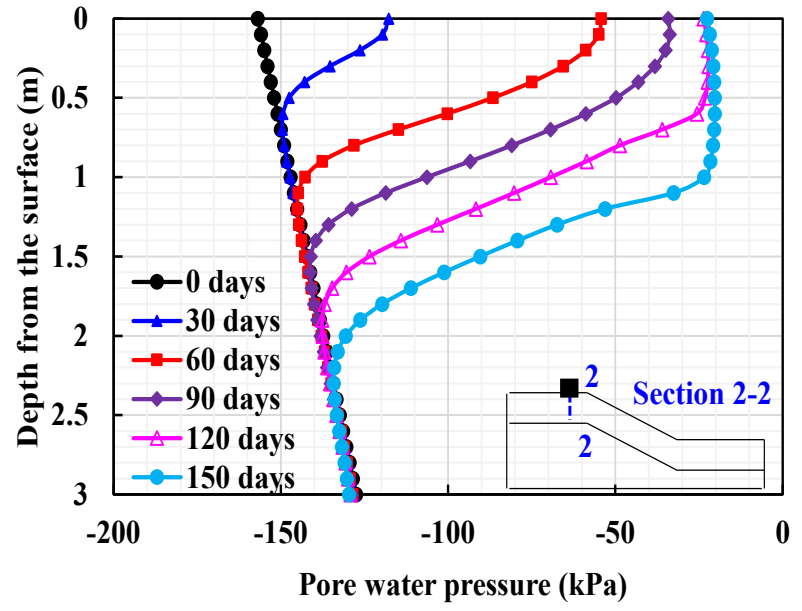

Fig. 4b Section 2-2

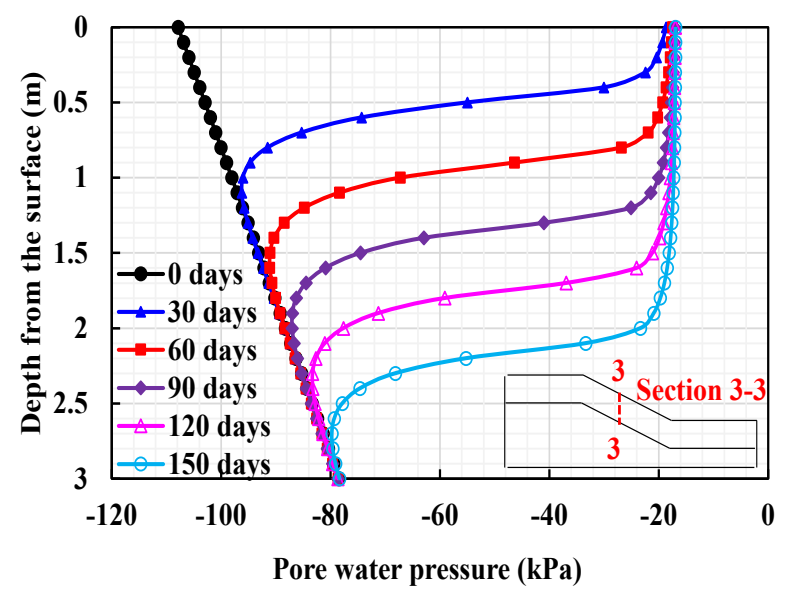

Fig. 4c Section 3-3

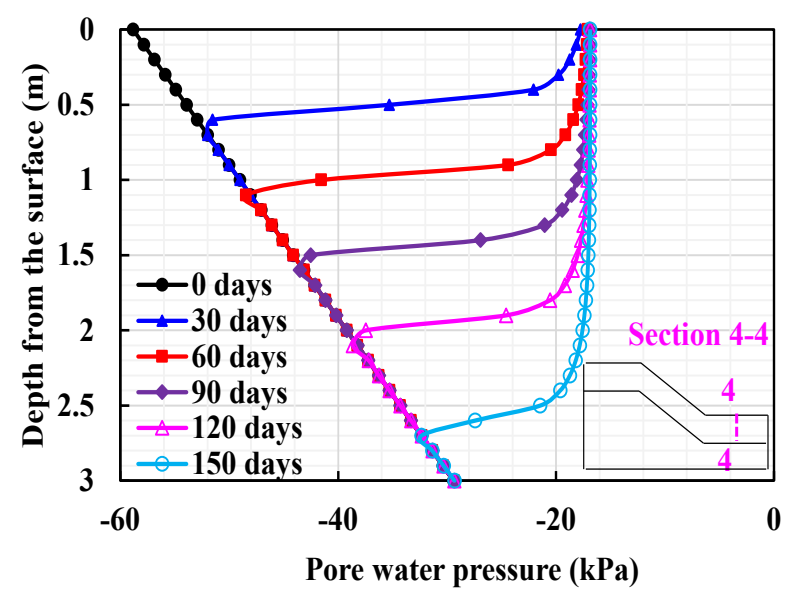

Fig. 4d Section 4-4

Fig. 4 Pore water pressure variation during rainfall at different locations

\subsection{Effect of rainfall on the foundation behavior}

Figure 5 shows the foundation vertical stress versus normalised displacement ratio, $d / B$. The shape of the curves in Figure 5 shows that the stress remains relatively constant. However, some of the curves do not attain a constant value (for example, curves of 0 day rainfall). Therefore, the ultimate bearing capacity can be determined by the graphical method used by several 
investigations (Costa et al. [27], Oh and Vanapalli [28]). The ultimate bearing capacity value is the intersection of the tangents to the initial elastic portion and the final portions of the stress versus displacement ratio curve shown in Figure 5 (i.e. $372 \mathrm{kPa}$ prior to rainfall).

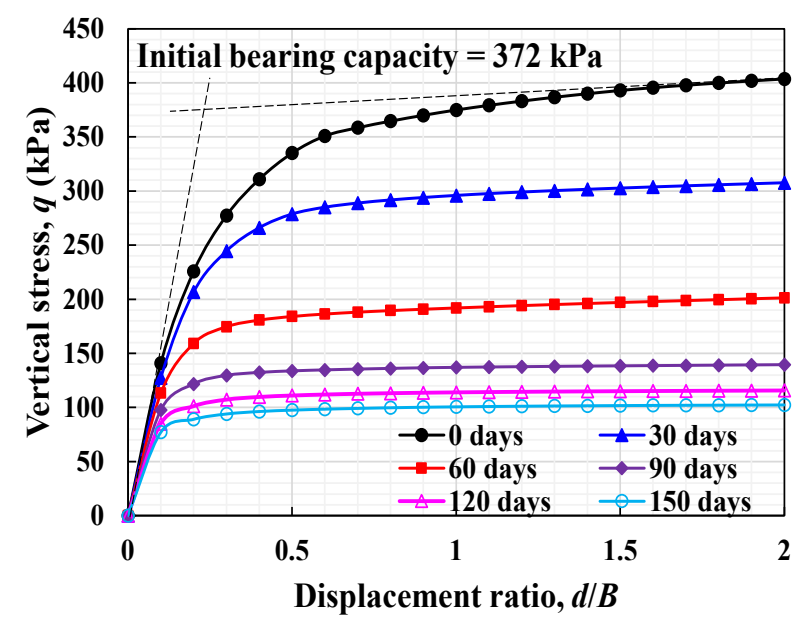

Fig. 5 Vertical stress versus displacement ratio of foundation for different rainfall durations

The ultimate bearing capacity for different rainfall durations is summarized in Table 2. It can be seen that the ultimate bearing capacity decreases with increasing rainfall duration. This is mainly attributed to the decrease of matric suction in the soil during the rainfall. The decreasing matric suction leads to a reduction in both the shear strength and the bearing capacity. The ultimate bearing capacity prior to rainfall is more than three times of that under 150 days of rainfall. Slight reduction in the bearing capacity was observed after 90 days of rainfall. Such a behavior suggests the bearing capacity of foundation reduces due to the influence of rainfall and reaches a constant value after a specific rainfall duration.

Table 2 Ultimate bearing capacity variation under different rainfall durations

\begin{tabular}{ccccccc}
\hline $\begin{array}{c}\text { Rainfall } \\
\text { duration (Days) }\end{array}$ & 0 & 30 & 60 & 90 & 120 & 150 \\
\hline $\begin{array}{c}\text { Ultimate } \\
\text { bearing } \\
\text { capacity (kPa) }\end{array}$ & 372 & 292 & 186 & 136 & 114 & 100 \\
\hline
\end{tabular}

\subsection{Effect of rainfall on the slope stability}

The slope stability is evaluated based on the FS of the slope derived from limit equilibrium methods in SLOPE/W. Morgenstern-Price method, (MP method, Morgenstern and Price [29]) has been adopted with halfsine side function. This method considers interslice shear and normal forces which results in a relative low FS compared to the simpler method such as the Bishop's Simplified method (GEO-SLOPE International Ltd. [30]). The FS is defined as the ratio of the soil shear strength, $\tau_{\mathrm{f}}$, to the shear stress, $\tau_{\mathrm{s}}$, on the slip surface (Eq. 3).

$$
\mathrm{FS}=\frac{\tau_{\mathrm{f}}}{\tau_{\mathrm{s}}}
$$

The critical FS of slope with respect to the rainfall duration is presented in Figure 6a and 6b. Figure 6a shows the critical FS of slope decreases from 1.93 to 1.59 during 150 days of rainfall without considering the foundation loading. A turning point at 120 days of rainfall on the critical FS curve has been found. The FS decreases dramatically after the turning point. This is mainly related to the slope failure mechanism and rainfall infiltration. The critical FS information can be obtained from the deep seated failure conditions shown in Figure 6a (Mechanism A), from initial conditions to 120 days of rainfall infiltration. However, the slope may have shallow surface failure mechanism (Mechanism B in Figure 6a) after 120 days. Such a type of failure mechanism is commonly observed in slope failures associated with rainfall infiltration. Water infiltrates into the surface soil first and contributes towards a decreasing matric suction; this characteristic behavior in turn results in shear strength reduction, which has been discussed earlier.

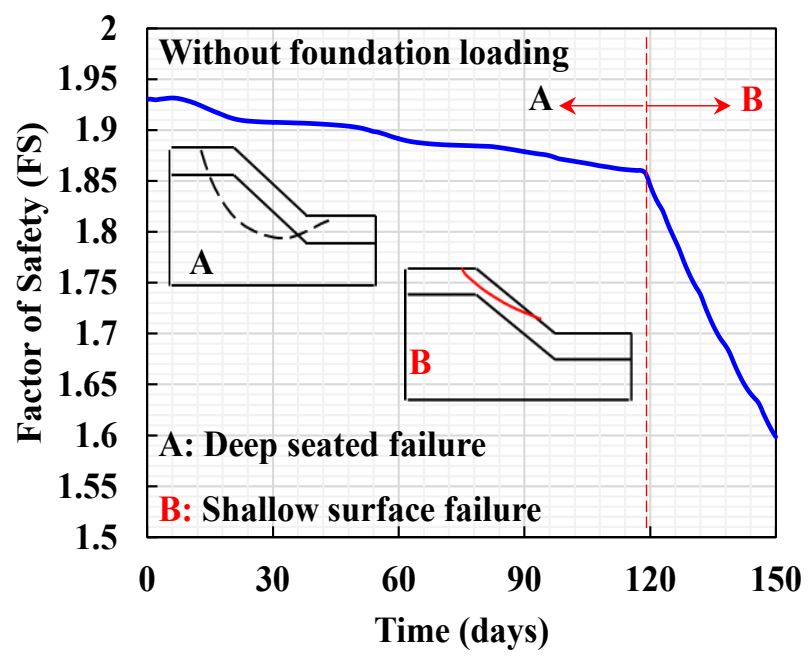

Fig. 6a Critical FS of slope without foundation loading.

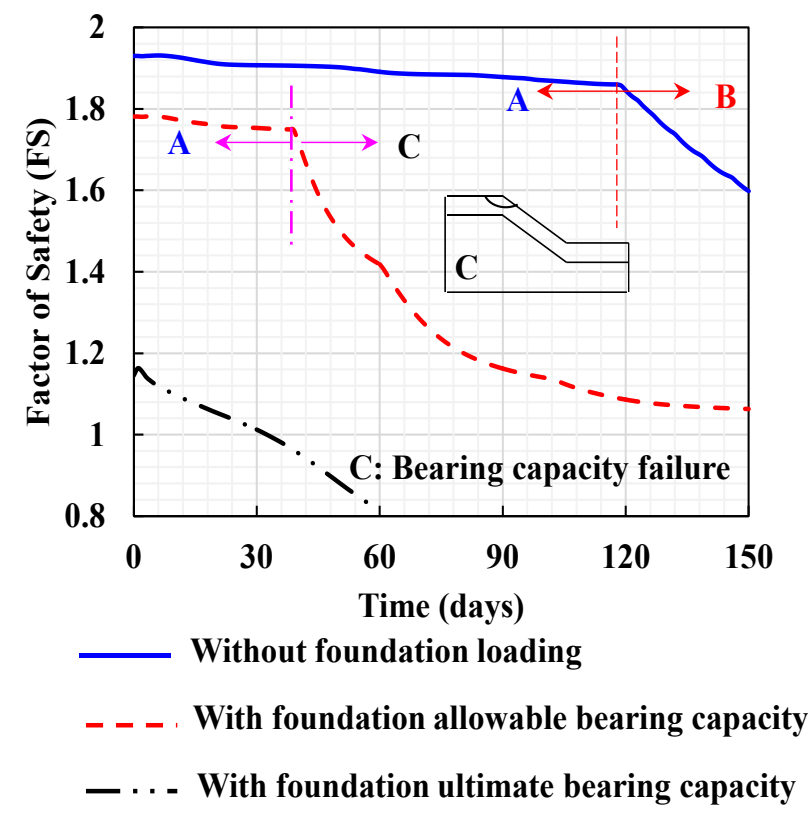

Fig. 6b Comparison of critical FS under different loading condition

Fig. 6 Relationship between critical FS and rainfall duration 
Figure $6 \mathrm{~b}$ provides comparisons between the slope critical FS under different loading conditions. The initial ultimate bearing capacity $372 \mathrm{kPa}$ has been applied as surcharge load along the slope surface below the foundation. Sharp decrease has been found on the slope FS from 1.14 to 0.81 in two months rainfall with the loading of foundation ultimate bearing capacity. The slope becomes unstable due to one months of rainfall. No turning point has been found for this loading condition. The bearing capacity failure has been found in this scenario shown in Figure 6b (Mechanism C).

The loading condition with allowable bearing capacity is also investigated. The allowable bearing capacity is estimated based on a FS value of 3 according to the AASHTO [31]. A turning point corresponding to a rainfall duration of 40 days has been found on the critical FS curve. Similar to the condition of slope without foundation loading, the critical FS reduces slightly first with a deep seated failure mechanism. This failure mechanism reflects that it is the slope geometry and soil properties that mainly control the slope critical FS, at this stage. However, a sharp decrease has been observed with the increasing rainfall duration after the turning point. The bearing capacity failure mechanism (Mechanism C) has been found. This means the combined influence of the foundation loading and the rainfall on the slope critical FS is obvious after 40 days of rainfall duration. It also can be seen in Figure $6 \mathrm{~b}$ that the critical FS of slope with foundation loading (both the ultimate bearing capacity loading and the allowable bearing capacity loading) decreases significantly compared to the slope without foundation loading.

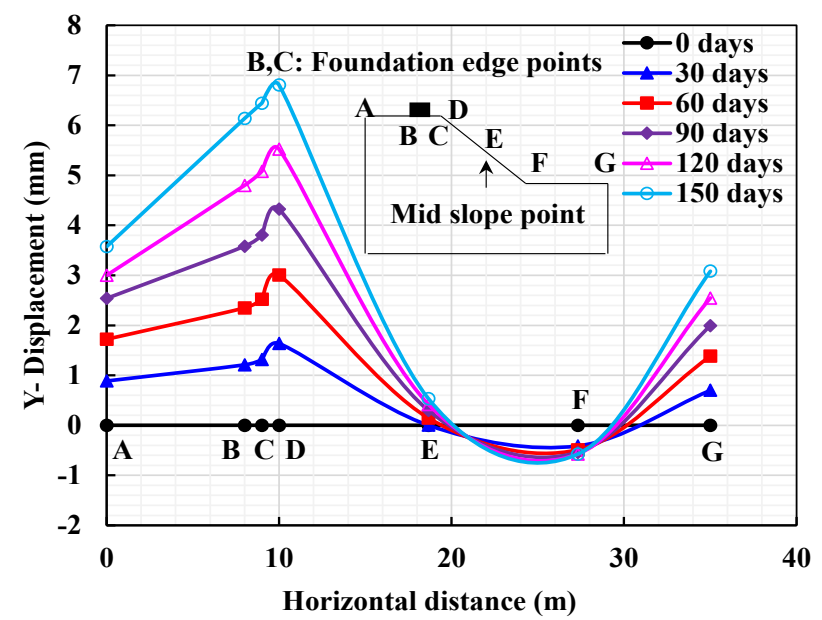

Fig. 7 Vertical displacement of slope surface

The soil volume change which is typically observed in expansive soils also has influence on the slope stability. Figure 7 shows the vertical displacement of the slope surface without foundation loading with respect to the horizontal distance (X coordinate) under different rainfall infiltration. The heave of the slope surface increases with the increasing rainfall duration. The maximum displacement is about $7 \mathrm{~mm}$ at point $\mathrm{D}$ in Figure 7 under 150 days of rainfall. This value is relatively small to contribute to a low FS compared to a low FS caused by the shear strength reduction under the rainfall. However, the surface heave can be a major concern to the infrastructure performance constructed in expansive soils, with relatively higher swelling pressure. It also can be seen in Figure 7 that the non-uniform heave of the slope surface has been found at each rainfall duration. The differential heave or settlement should be considered in the rational design of foundations in expansive soils. These aspects are not discussed in this study because of space limitations.

\section{Conclusions}

In this paper, numerical modelling of the infrastructure foundation and slope system of expansive soils is conducted taking account of the influence of rainfall infiltration with the aid of commercial software Geostudio. The hydro-mechanical coupling analysis is conducted with SIGMA/W followed by the load deformation analysis on the foundation and slope stability analysis with SLOPE/W. The relationship between the unsaturated soil properties and the matric suction has been considered in the numerical model. The bimodal SWCC related to the cracked soil has been included in the numerical modeling for rigorous analyses.

The following conclusions are derived based on the results obtained from the present study:

(1) The rainfall infiltration has significant influence on the pore water pressure profiles with respect to the depth. The pore water pressure profiles beneath the foundation are different from the ground without foundation cover. The wetting front advances at a relatively slow rate beneath the foundation. Overall, the matric suction decrease sharply with the rainfall water infiltration and is a key factor that results in the reduction of the shear strength and the foundation bearing capacity.

(2) The foundation bearing capacity decreases dramatically with an increase in the rainfall duration. The bearing capacity is inferred to reach a constant value after a specific rainfall duration based on the results of this study.

(3) The critical FS of the slope under both loading and unloading condition reduces with increasing rainfall duration. Three different failure mechanisms may occur under the rainfall infiltration which depend on the slope loading condition and the rainfall duration.

(4) The influence of volume change to the slope stability in this study is not obvious compared to the shear strength reduction. Such a behavior may be attributed to higher value of modulus of elasticity. More research studies are required to understand the influence of heave on the slope stability and differential settlement of infrastructures foundations in expansive soils, in future.

\section{Acknowledgements}

The first author gratefully acknowledges the China Scholarship Council - uOttawa, Canada Joint Scholarship for her Ph.D. program. The second author thanks the support from NSERC, Canada for the research programs. 


\section{References}

1. N. Khalili, M.H. Khabbaz, S. Valliappan (2000). Effective stress based numerical model for hydromechanical analysis in unsaturated porous media. Comput. Mech. 26: 2, 174-184.

2. S. Qi, S.K. Vanapalli (2015). Hydro-mechanical coupling effect on surficial layer stability of unsaturated expansive soil slopes. Comput. Geotech. 70, 68-82.

3. L. Pantelidis, D.V. Griffiths (2015). Footing on the Crest of Slope: Slope stability or Bearing Capacity. Eng. Geol. Soc. Territ. 2, 1231-1234.

4. E. Baah-Frempong, S.K. Shukla (2018). Stability analysis and design charts for a sandy soil slope supporting an embedded strip footing. Int. J. GeoEngineering. 9, 1, 1-23.

5. K.Y. Choi, R.W.M. Cheung (2013). Landslide disaster prevention and mitigation through works in Hong Kong. J. Rock Mech. Geotech. Eng. 5, 5, 354-365.

6. G.G. Meyerhof (1957). The Ultimate Bearing Capacity of Foundations on Slopes. Proc. Fourth Int. Conf. Soil Mech. Found. Eng. London. August, 384-386.

7. D. Shields, N. Chandler, J. Garnier (1990). Bearing capacity of foundations in slopes. J. Geotech. Eng. 116, 3, 528-537.

8. D. Raj, Y. Singh, S.K. Shukla (2018). Seismic bearing capacity of strip foundation embedded in $c-\phi$ soil slope. Int. J. Geomech. 18, 7, 1-16.

9. A. Dey, R. Acharyya, A. Alammyan (2019). Bearing capacity and failure mechanism of shallow footings on unreinforced slopes: a state-of-the-art review. Int. J. Geotech. Eng.

10. C. Li, A. Zhou, P. Jiang (2020). Eccentric bearing capacity of embedded strip footings placed on slopes. Comput. Geotech. 119, November 2019, 103352.

11. S.K. Vanapalli, F.M.O. Mohamed (2013). Bearing capacity and settlement of footings in unsaturated sands. Int. J. Geomate. 5: 1, 595-604.

12. W.T. Oh, S.K. Vanapalli (2011). Modelling the applied vertical stress and settlement relationship of shallow foundations in saturated and unsaturated sands. Canadian Geotech. J. 48, 425-438.

13. T.M.H. Le, D. Gallipoli, M. Sanchez, S. Wheeler (2013). Rainfall-induced differential settlements of foundations on heterogeneous unsaturated soils. Géotechnique 63, 15, 1346-1355.

14. Y. Kim, H. Park, S. Jeong (2017). Settlement behavior of shallow foundations in unsaturated soils under rainfall. Sustain. 9, 1417.

15. Y. Tang, H.A. Taiebat, A.R. Russell (2017). Bearing capacity of shallow foundations in unsaturated soil considering hydraulic hysteresis and three drainage conditions. Int. J. Geomech. 17, 6, 04016142.
16. V. Mahmoudabadi, S.M. Asce, N. Ravichandran, D. $\mathrm{Ph}, \mathrm{M}$. Asce (2019). Design of Shallow Foundation considering Site-Specific Rainfall and Water Table Data : Theoretical Framework and Application. Int. J. Geomech. 19, 7, 04019063.

17. C.W.W. Ng, L.T. Zhan, C.G. Bao, D.G. Fredlund, B.W. Gong (2003). Performance of an unsaturated expansive soil slope subjected to artificial rainfall infiltration. Géotechnique. 53, 2, 143-157.

18. M.S. Khan, S. Hossain, A. Ahmed, M. Faysal (2017). Investigation of a shallow slope failure on expansive clay in Texas. Eng. Geol. 219, 118-129.

19. Geo-Slope Int. Ltd, Geo-studio 2018 R2.

20. R.T. Yoshida, D.G. Fredlund, J.J. Hamilton (1983). The prediction of total heave of a slab-on-ground floor on Regina clay. Can. Geotech. J. 20, 1, 69-81.

21. S. Azam, M. Ito (2011). Unsaturated soil properties of a fissured expansive clay. 14th Pan-American Conf. Soil Mech. Geotech. Eng.

22. J.H. Li, L.M. Zhang, X. Li (2011). Soil-water characteristic curve and permeability function for unsaturated cracked soil. Can. Geotech. J. 48, 7, 1010-1031.

23. F. Shuai (1996). Simulation of swelling pressure measurements on expansive soils. Doctor of Philosophy thesis.

24. S.K. Vanapalli, D.G. Fredlund, D.E. Pufahl, A.W. Clifton (1996). Model for the prediction of shear strength with respect to soil suction. Can. Geotech. J. 33, 3, 379-392.

25. W.T. Oh, S.K. Vanapalli, A.J. Puppala (2009). Semiempirical model for the prediction of modulus of elasticity for unsaturated soils. Can. Geotech. J. 46, 8, 903-914.

26. H.H. Adem, S.K. Vanapalli (2013). Constitutive modeling approach for estimating 1-D heave with respect to time for expansive soils. Int. J. Geotech. Eng. 7, 2, 199-204.

27. Y.D. Costa, J.C. Cintra, J.G. Zornberg (2003). Influence of matric suction on the results of plate load tests performed on a lateritic soil deposit. Geotech. Test. J. 26, 2, 219-227.

28. W.T. Oh, S.K. Vanapalli (2013). Interpretation of the Bearing Capacity of Unsaturated Fine-Grained Soil Using the Modified Effective and the Modified Total Stress Approaches. Int. J. Geomech. 13, 6, 769-778.

29. N. U. Morgenstern, V. E. Price (1965). The analysis of the stability of general slip surfaces. Géotechnique. 15, 1, 79-93.

30. Geo-SLOPE International Ltd. (2012). Stability modeling with $S L O P E / W, \quad$ An Engineering Methodology.

31. AASHTO (2014). LRFD Bridge Design Specifications, Seventh Edition. 